\title{
A OBRA LITERÁRIA PARA A INFÂNCIA E A JUVENTUDE DE LUÍS SEPÚLVEDA
}

\author{
Ângela Balça (Universidade de Évora - CIEC) \\ Fernando Azevedo (Universidade do Minho - CIEC)
}

\begin{abstract}
Resumo: A Literatura, obediente ao protocolo da ficcionalidade, não deixa, porém, de suscitar, nos seus leitores, importantes e significativos efeitos perlocutivos. Este artigo analisa três títulos de potencial recepção leitora infanto-juvenil da autoria do reconhecido e premiado autor chileno Luís Sepúlveda, enfatizando os seus eixos semântico-temáticos fundamentais. As obras, mantendo uma natureza estética, não deixam de interrogar o mundo e suscitar uma reflexão lata sobre os valores, em particular os valores da Alteridade e do seu reconhecimento pelo sujeito.
\end{abstract}

Palavras-chave: Literatura infanto-juvenil; Fábula; Valores; Alteridade.

Abstract: The Literature, compliant to the fiction of the protocol, still evokes in its readers, important and significant perlocutionary effects. This article examines three titles of potential juvenile reading acceptation from the recognized and awarded Chilean author Luis Sepulveda, emphasizing their fundamental semantic-themes. The works, while maintaining an aesthetic nature, they nevertheless question the world and raise a broad reflection on the values, particularly the values of Otherness and its recognition by the subject.

Key-words: Literature; Values; Reader.

\section{INTRODUÇÃO ${ }^{1}$}

Reconhecido e premiado autor chileno, jornalista e ativista político, Luís Sepúlveda possui, na sua vasta obra, alguns títulos de potencial recepção leitora infanto-juvenil. Referimo-nos às obras História de uma gaivota e do gato que a ensinou a voar (SEPÚLVEDA, 2002), História de um gato e de um rato que se 
tornaram amigos (SEPÚLVEDA, 2013a) e História de um caracol que descobriu a importância da lentidão (SEPÚLVEDA, 2014).

A escrita de literatura para os mais novos de Luís Sepúlveda obedeceu a um impulso que trazemos aqui na primeira pessoa: "Apercebi-me de que os livros escritos para crianças não eram para pequenos leitores, mas para pequenos idiotas. Eram completamente manipuladores. Não gostei." (PIMENTA, 2013, s/p). E desta constatação, feita em relação aos livros que os seus filhos tinham de ler para a escola, nasceu a obra de literatura para a infância deste escritor. Consideramos interessante voltar às suas palavras, sobre a escrita no âmbito desta matriz literária:

É muito difícil. Trato com muito respeito os pequenos leitores. Sei que exigem uma linguagem directa, são inimigos da ambiguidade. Gostam que contemos histórias com frases curtas, gostam de contos de que se possam lembrar. (...) $\mathrm{O}$ que nós queremos dos leitores é que eles gostem do que escrevemos. Que gostem da história. (PIMENTA, 2013, s/p)

Deste modo, são estas convicções e a paleta de valores deste escritor e ativista que enformam as obras que nos propomos abordar neste artigo, já mencionadas anteriormente.

Todos os textos, com um título cujo incipit remete para a tradição do discurso hagiográfico e, nessa medida, sugere 
estar-se perante um relato edificante e de potenciais e importantes efeitos perlocutivos, exibem exempla de situações, comportando valores relevantes para o sujeito em formação. Com efeito, o primeiro dos textos selecionados explora a importância do Outro e do seu respeito escrupuloso num processo educativo, o segundo texto exibe, com exemplos práticos, o sentido do conceito de amizade e de felicidade, enquanto que o terceiro sublinha a importância da capacidade de ação e de liderança num mundo governado pela passividade.

Relevante parece-nos ser o fato de estes textos de Luís Sepúlveda irem ao encontro do pensamento de Patrício (1996) que afirma a neutralidade axiológica do discurso como uma falácia ou uma impossibilidade. Partilhamos do princípio de que a literatura (e a literatura para a infância e juventude) não é neutra, não é inócua, encerrando os textos diversas formas de exibirem valores. O modo como estes valores estão plasmados nos textos pode ser distinto. Caberá ao leitor e ao mediador de leitura exercer sobre esses textos um trabalho hermenêutico, de exegese, para trazer à luz, não só a dimensão estética do texto, mas também, a sua dimensão axiológica.

A literatura infanto-juvenil, atendendo aos seus destinatários preferenciais, não deixa de manifestar um 
propósito veladamente formativo (INNOCENTI, 2000). Ela busca, como afirmamos noutro lugar (AZEVEDO, 2011), contribuir com o seu significado conotativo para promover um desenvolvimento espiritual e intelectual do formando (BRESSAN, 1984) e, nesse sentido, predominam aí os ritos de passagem e os percursos de iniciação do jovem ao mundo dos adultos, metáforas variadas de caminhos múltiplos para um mais lato conhecimento individual.

\section{HISTÓRIA DE UMA GAIVOTA E DO GATO QUE A ENSINOU A VOAR}

Recomendada pelo Plano Nacional de Leitura, a obra História de uma gaivota e do gato que a ensinou a voar (SEPÚLVEDA, 2002), constitui um curioso texto não só pelo modo hábil como nos narra a história de Ditosa - a jovem gaivota, criada e alimentada pelos gatos do porto -, como também pelos valores éticos que propõe. Aqui encontramos, com efeito, uma série de situações que possibilitam a um leitor ainda pouco experiente nos chamados bosques da ficção refletir sobre aspectos essenciais da vida do sujeito com, por exemplo, o significado do cumprimento da palavra dada, a importância da honra, o valor da amizade ou o que implica a aceitação, sem condicionamentos, do Outro. Esta importante dimensão axiológica, que abarca também uma reflexão sobre o lugar do homem e dos animais num planeta 
cujo desenvolvimento se deseja sustentado, é dada a ler por meio de um discurso alegórico e simbólico.

O título da obra constitui, desde logo, um elemento portador de novidade semiótica. Ele defrauda, com efeito, ostensivamente determinadas expectativas consistentes com o quadro de referência do mundo empírico e históricofactual. Nesta linha de pensamento, tomamos como exemplo a não compatibilidade física e comportamental, de acordo com os quadros de referência comuns, entre o felino e o ser voador, fato que causa espanto e estranhamento, anunciando simultaneamente um determinado processo educativo de crescimento, aprendizagem e autonomia e um certo caracter de exemplaridade desta mensagem. É de notar que este processo é, pelo tempo verbal utilizado (o pretérito perfeito), entendido como concluído e aparentemente pertencente ao modo da realidade factual.

Múltiplos planos se cruzam nesta obra: elementos que remetem para a verticalidade em oposição à horizontalidade, a que se associam simbolicamente aspectos como os da dicotomia céu/terra, vida/morte, luz/sombra ou ainda comunhão/separação ou utopia/distopia.

A narrativa inicia-se com o voo do bando de gaivotas em céu aberto no mar do Norte, e onde a liberdade, a 
Vida, a comunhão, a alegria ou a Luz constituem isotopias dominantes. A estas contrapõem-se outras: a nãoverticalidade, a terra, as sombras, a separação ou o caos, indícios graças aos quais podemos ler a presença ostensiva da morte ou da distopia.

Zorbas é um negro, gordo e grande gato, um ser intrinsecamente marcado pela sua alteridade face aos seus progenitores e igualmente face ao quadro de referências próprio de uma cultura popular, uma vez que não é reconhecido pelo pelicano que o confunde com uma rã nem tão pouco partilha os traços que estereotipadamente caracterizariam os seres da sua espécie: o pelo de listras cinzentas, a velocidade, a agilidade ou o cheirar a pantufa. O gato Zorbas recebe então a missão de criar, desde o momento anterior ao seu nascimento, a jovem gaivota Ditosa, ensinando-Ihe tudo o que ela necessitará para poder integrar o grupo da sua espécie. Este processo educativo, que abarca o grosso da narrativa, incluirá o chocar do ovo, a alimentação da jovem cria, a sua defesa em momentos particularmente difíceis, sempre num quadro de respeito e de crescente autonomia, até à sua emancipação total: o ensiná-la a voar e o assistir, afetivamente, essa sua iniciação. 
Criada por Zorbas e pelos gatos do porto, que respondem solidariamente a um pedido de auxílio endereçado pelo negro, gordo e grande gato, a pequena gaivota sente-se tão bem entre aqueles que a cuidam que quer renunciar à sua condição de ave e ser gato como eles. Se a ausência de pontos de referência adequados às suas características de ser voador motiva nela uma crise de identidade, essa crise é rapidamente superada graças a um ambiente de compreensão e de profundo respeito por todos os que a rodeiam e educam:

Contigo aprendemos a apreciar, a respeitar e a gostar de um ser diferente. É muito fácil aceitar e gostar dos que são iguais a nós, mas fazê-lo com alguém diferente é muito difícil, e tu ajudastenos a consegui-lo. És uma gaivota e tens de seguir o teu destino de gaivota.

Tens de voar. Quando o conseguires, Ditosa, garanto-te que serás feliz, e então os teus sentimentos para conosco e os nossos para contigo serão mais intensos e belos, porque será a amizade entre seres totalmente diferentes. (SEPÚLVEDA, 2002, p. 92-93)

A osmose entre mundos possíveis à partida não compatíveis entre si - o mundo dos animais e o mundo dos humanos e o diálogo que entre eles se estabelece - constitui uma forma de alertar o leitor para as possíveis mensagens de 
natureza ideológica que este texto comporta, recuperando simultaneamente uma isotopia que já fora, num momento inicial da narrativa, explorado: o da comunicação entre os animais versus o da incomunicabilidade entre os humanos. Com efeito, se os animais têm uma linguagem universal, possuindo, inclusive, a capacidade de compreender o Outro - Zorbas quebrará o tabu e falará a linguagem dos humanos (SEPÚLVEDA, 2002)-, os humanos, pelo contrário, procurando, a todo o custo, uma explicação racional para tudo, manifestam uma forte dificuldade em comunicar entre si e particularmente com o Outro, não o reconhecendo como seu semelhante.

A conclusão do processo educativo da jovem gaivota é atingida quando esta, incentivada pelos amigos felinos e apoiada pelo Poeta, concretiza o seu primeiro voo. O local da sua emancipação coincide com o mesmo espaço físico que Kengah, a gaivota progenitora, avistara na sua última tentativa de voar: a torre de São Miguel.

A coincidência do espaço e a sua associação ao binómio morte versus vida torna-o num lugar simbólico: a mãe termina aqui o seu voo, a filha inicia-o. A jovem gaivota tem de prosseguir o voo da mãe, interrompido pelos humanos, tal como tinha dito Colonello. Este espaço tem características próprias: está muito distanciado do solo, é um espaço 
aberto e amplo, fato que atrai as aves, pela sua tendência à liberdade, às alturas, ao vaivém constante em que vivem. É nesta torre, e num momento de clímax narrativo, que o maravilhoso acontece: a cria de um gato aprende a voar! Se o espaço possui, como já assinalamos, um forte simbolismo, este manifesta-se também no que respeita à hora escolhida para o voo iniciático: as doze badaladas da meia-noite. Este tanger das badaladas representa, à semelhança do que ocorre em numerosos textos de literatura infantil que fazem parte do património coletivo dos chamados contos de fadas, a revelação de grandes transformações: é, com efeito, ao som das doze badaladas da meia-noite, dado pelos sinos da igreja de São Miguel, e numa noite de chuva, que a jovem gaivota, acompanhada apenas por Zorbas e pelo Poeta, se emancipa e atinge a sua maturidade. Não porque fora ensinada a voar, mas porque, vencendo os seus receios, ousou dar o primeiro passo! O campanário da torre da Igreja de São Miguel constitui, pois, a fronteira simbólica que permite à jovem gaivota acreditar que poderá ser feliz, retomando a sua condição autêntica de ser intrinsecamente livre e capaz de voar,

- Estou a voar! Zorbas! Sei voar! grasnava ela, eufórica, lá da vastidão do céu cinzento. 
O humano acariciou o lombo do gato.

- Bem, gato, conseguimos - disse ele suspirando.

- Sim, à beira do vazio compreendeu o mais importante - miou Zorbas.

- Ah, sim? E o que é que ela compreendeu? - perguntou o humano.

- Que só voa quem se atreve a fazê-lo miou Zorbas. (SEPÚLVEDA, 2004, p. 121)

Se a narrativa pode ser entendida nesta perspetiva de educação e de crescente autonomia da gaivota, esta obra pode, de igual modo, ser lida como uma mensagem onde se apela a um intenso prazer de viver. De fato, Kengah, a gaivota, luta por sobreviver à trágica maré negra e, vendo-se sem possibilidades, quer que a sua descendência continue, deixando um ovo, para que Zorbas faça aquilo que ela já não pode fazer. Zorbas, ajudado pelos seus amigos, trava uma luta constante por vencer as dificuldades e o sofrimento e enfrenta os problemas que vão surgindo, com coragem e determinação, dominando, assim, os obstáculos e saindo vitorioso.

Tratando-se de um texto literário lido por crianças e jovens, encontramos aqui uma clara dicotomia entre personagens positivas e personagens negativas. Se a censura endereçada pela gaivota Kengah aos humanos por poluírem os mares poderia levar o leitor a estabelecer uma 
visão maniqueística do tipo humanos maus versus animais bons, a capacidade de reflexão e de distinção entre o bem e o mal que esta personagem manifesta relativamente a outras personagens humanas, nomeadamente os homens das "pequenas embarcações decoradas com as cores do arco-íris" (SEPÚLVEDA, 2002, p.25), associada à existência de personagens animais com comportamentos claramente disfóricos, invalida esta visão maniqueísta do mundo e constitui mais um meio de permitir a emergência de valores éticos profundamente educativos. De fato, a cosmovisão que aqui se apresenta jamais é a de um mundo "inteiramente a Branco e Preto" (CESARINY, 1980, p. 66), mostrando-se, pelo contrário, que em cada espécie há personagens positivas e personagens negativas e que compete a cada um saber distingui-las e agir em conformidade.

Quando olhamos com cuidado para as personagens humanas, verificamos que, para além dos homens das "pequenas embarcações decoradas com as cores do arcoíris" (SEPÚLVEDA, 2002, p. 25), já supra referidos, há mais dois seres que são particularmente valorizados: o garoto que cuida de Zorbas, e cuja caracterização é feita pelo narrador de forma indireta, e um humano que tem a particularidade de fazer voar as palavras. É significativo que as únicas 
personagens humanas claramente participantes na ação sejam uma criança e um poeta, este último com a chave capaz de impulsionar decisivamente a jovem gaivota a voar.

Em conclusão, diremos que esta obra, narrando, na perspetiva de uma fábula, uma história de amor e de profundo respeito pelo Outro, cumpre importantes efeitos perlocutivos, ao alertar os leitores para aspetos fundamentais da vida em sociedade. A amizade, a bondade, a solidariedade, a generosidade, o amor à vida, a aceitação e a convivência pacífica da diversidade dos seres, o respeito pela natureza pessoal e individual de cada um, bem como a profunda mensagem de autoconfiança na possibilidade de cumprimento de um sonho são elementos fundamentais do universo ideológico aqui presente e que emergem da interação que o leitor estabelece com o texto.

Se um dos maiores desafios que, nos dias de hoje, se colocam à escola é o "da diversidade, da diferenciação, do multiculturalismo, assumindo que educar para a cidadania é também educar para o reconhecimento, para o respeito e para a cultura da diferença" (FONSECA, 2000, p. 19), é nossa opinião que esta fábula pode constituir-se como uma preciosa ajuda na educação para a tolerância e para o exercício da cidadania. 
Com efeito, não impondo nenhuma moral, nem assumindo explicitamente intenção didático-pedagógica, mas sendo efetivamente um texto que, pela sua forma de conteúdo e de expressão, comporta a novidade semiótica que define e caracteriza a literariedade, ele permite que o leitor reconheça uma série de valores éticos fundamentais à nossa vivência em sociedade. Neste sentido, este texto pode, de uma forma que se nos afigura muito produtiva, iniciar os seus jovens leitores naquilo que a investigadora Pires apelida "o caminho da aceitação enriquecedora da diversidade" (1996, p.105).

\section{HISTÓRIA DE UM GATO E DE UM RATO QUE SE TORNARAM AMIGOS}

Inaugurada com uma dedicatória aos gatos, na qual o autor textual explicitamente assume que a narrativa procura dar voz ao silêncio do gato Mix, Luís Sepúlveda (2013a), mais uma vez, retoma a imagem de um gato preto, que estabelece amizade primeiramente com uma criança (Max), o filho do autor textual, e, seguidamente, com um rato, ser inusitado e não compatível consigo, de acordo com os quadros de referência comuns (gato - predador vs rato - alimento).

Na verdade, "A história do livro é profundamente biográfica. Qualquer semelhança entre o Max e o Mix não é pura coincidência. Max é um dos filhos de Sepúlveda. O gato Mix 
existiu mesmo." (PIMENTA, 2013, s/p), afirma Paulo Galindro, o ilustrador da edição portuguesa desta obra. Os gatos são animais caros a Luís Sepúlveda, que conta que um astrólogo chinês lhe terá dito que, noutra vida, ele teria sido o gato de um mandarim (PIMENTA, 2013). O escritor confidencia "Um gato feliz. (...) Gosto de acreditar nisso. (...) Tenho uma química especial com eles. Todos os gatos se aproximam de mim, nenhum se afasta." (PIMENTA, 2013, s/p)

Nesta obra, o gato Mix possui uma particularidade: é um gato preto com um perfil grego, adotado por uma criança que cresce e se torna um adolescente e um jovem. Maior de idade, Max aluga um apartamento, para onde vai viver com o gato. Aí, Max e o gato partilham um mesmo espaço, com admiração mútua e amizade. Max preocupa-se com o gato, da mesma forma que Mix cuida da despensa, garantindo que os ratos não se aproximam da embalagem de cereais com chocolate preferidos de Max.

A narrativa acompanha e descreve o processo de envelhecimento do gato, a sua cegueira, as suas limitações e o modo positivo como as pode superar, graças à amizade que estabelece com um pequeno rato tagarela.

É o gato Mix quem, respondendo a um pedido do rato, o vai nomear, dando-lhe o nome de Mex (de rato mexicano). 
Este ato individualizador está repleto de simbolismo. Dar um nome significa reconhecer o Outro como semelhante ao sujeito, emancipá-lo da massa informe, conferir-lhe uma legitimidade e durabilidade sociais.

A partir desse momento simbólico, a amizade entre gato e rato estreita-se e o rato passa a assumir, cada vez mais, a função de visualizador que orienta e ajuda o gato cego a agir.

Os dois seres, frágeis nas suas individualidades respectivas, mostram-se, na união e cooperação de um com o outro, potentemente fortes ao ponto de conseguirem afugentar um ladrão, que tentara assaltar o apartamento, ou conseguirem inclusivamente transcender a sua natureza e voar. Graças à visão de Mex, o gato recupera, em cima do telhado, a sua dimensão majestosa:

Foi um voo curto, mas Mix sentiu o ar que lhe batia no focinho, a elegância das suas patas dianteiras prontas a apoiarse, a liberdade estonteante de se saber ainda capaz de saltar de um telhado para outro e, ao sentir novamente uma superfície sólida sob as patas, agradeceu ao ratinho que lhe emprestara os olhos. (SEPÚLVEDA, 2013a, p. 62)

A narrativa está recheada de aforismos que, graficamente destacados do texto, em letras maiúsculas, e com um fundo colorido, enfatizam o valor e a importância da amizade. 
Nota-se que existe uma gradação na qualificação atribuída aos amigos, à medida que a narrativa vai evoluindo e se vai aproximando do seu clímax: "os amigos entreajudam-se. Ensinam-se mutuamente. Partilham as vitórias e os erros" (SEPÚLVEDA, 2013a, s/p), “os amigos velam pela alegria um do outro" (SEPÚLVEDA, 2013a, s/p), "os amigos velam sempre pela liberdade um do outro" (SEPÚLVEDA, 2013a, p.16), "os amigos compreendem as limitações do outro e ajudam-no" (SEPÚLVEDA, 2013a, p. 18), “os verdadeiros amigos também partilham o silêncio" (SEPÚLVEDA, 2013a, p. 18), "os verdadeiros amigos cuidam sempre um do outro" (SEPÚLVEDA, 2013a, s/p), "os verdadeiros amigos partilham os sonhos e as esperanças" (SEPÚLVEDA, 2013a, p. 27), "os verdadeiros amigos também partilham as pequenas coisas que alegram a vida" (SEPÚLVEDA, 2013a, p. 40), "e nunca, nunca, devemos enganar os amigos" (SEPÚLVEDA, 2013a, p. 42), "os amigos, quando estão unidos, não podem ser vencidos" (SEPÚLVEDA, 2013a, p. 52), "os verdadeiros amigos ajudam-se mutuamente a superar qualquer dificuldade" (SEPÚLVEDA, 2013a, p. 55), "os melhores amigos partilham o melhor que têm" (SEPÚLVEDA, 2013a, p. 64).

O texto obedece à tradicional fórmula do happy end, com a felicidade perene dos dois amigos: o gato já idoso e 
cego e o rato, que o defende, Ihe faculta alimento e o ajuda a ver aquilo que os seus olhos já não alcançam. A união entre os dois amigos é tal que a dupla gato-rato se torna, inclusivamente, motivo de conversa na vizinhança, percebida como insólita e não comum, mas simbolicamente lida como uma materialização da felicidade:

Max, Mix e Mex viveram vários anos naquele apartamento de Munique. Às vezes, um carteiro, enquanto estacionava a sua bicicleta amarela, olhava para o alto e julgava ver um gato de perfil grego sentado na beira do telhado junto do que lhe parecia ser um pequeno animal de pelúcia. Outras vezes, uma vendedora de túlipas da feira dos sábados, que costumava suspirar olhando para o céu, estremecia com o salto de um gato de peito branco e dorso preto, que saltava de um telhado para outro levando sobre o pescoço um estranho adorno castanhoclaro. (...) Amigos, não sei se estou a ver coisas estranhas, mas no telhado de uma casa pareceu-me ver um gato de perfil grego e um rato a admirarem o pôr do sol, e o mais curioso é que o gato parecia ouvir atentamente o rato. (...) Durante o tempo que o gato e o rato partilharam, longo ou breve, isso não tem importância porque a vida se mede pela intensidade com que é vivida, Mix viu com os olhos do seu pequeno amigo e Mex tornou-se forte com o vigor que emanava do seu amigo grande. 
$E$ os dois foram felizes porque sabiam que os verdadeiros amigos partilham 0 melhor que têm. (SEPÚLVEDA, 2013a, p. 63-64)

No fundo, esta curta narrativa, em jeito de fábula, fala sobre a evolução dos seres (o crescimento e juventude do humano Max, em paralelo ao crescimento e velhice do gato Mix), o valor da amizade entre humanos e animais e entre seres aparentemente não compatíveis de acordo com os quadros de referência comuns (o gato e o rato) e o significado profundo do conceito de felicidade, dado a ler já pela ilustração que a capa da obra apresenta: em cima de um tapete circular, os três amigos deitados a dormir, sorridentes, as caudas do gato e do rato a replicarem essa forma circular, símbolo geométrico, por excelência, da perfeição, tal como é sublinhado por Michel Cazenave (2007, p. 110-112), na Encyclopédie des Symboles.

Potencialmente dirigida a crianças e a jovens, aqui encontramos sempre um toque de humor, como, por exemplo, na auto-caraterização e comportamento manifestado pelo rato Mex, capaz de contar cem versões diferentes de um mesmo episódio.

Esta obra configura-se como um hino à amizade e à entreajuda, à cooperação entre todos. A narrativa deixa bem 
claro que não há inimigos naturais. Ainda que gato e rato possam constituir elementos de uma cadeia alimentar, tal cadeia pode ser interrompida e definidos novos papéis para esses sujeitos. Tal como acredita Luís Sepúlveda, “os gatos e os ratos não são inimigos. A inimizade é um conceito criado pelos humanos. Não existe na natureza. É uma categoria moral, uma invenção nossa." (PIMENTA, 2013, s/p). Com um coração bom, todos podem cooperar e entreajudar-se, sendo nessa amizade profunda, que inclui também o respeito pela individualidade de cada um, que reside a consecução da felicidade. Terminamos com as palavras de Luís Sepúlveda

Esta história é um hino à amizade e à unidade. Dois seres tão diferentes podem ajudar-se. (...) Um está velho e limitado porque é cego, outro é pequeno e débil. Mas são capazes de unir os seus projetos e chegar a algo. (PIMENTA, 2013, s/p)

\section{HISTÓRIA DE UM CARACOL QUE DESCOBRIU A IMPORTÂNCIA DA LENTIDÃO}

Publicada em 2014, esta é uma narrativa que ajuda o jovem leitor a perspectivar o mundo de um modo alternativo. Dedicada aos netos do autor, ao longo da narrativa explicase a razão da lentidão dos caracóis do jardim. Mais uma vez, as palavras de Luís Sepúlveda levam-nos para o seu mundo e para a sua arte de criar, 
Tenho cinco netos. O que tem 11 anos, chamado Daniel, vive em Gotemburgo (Suécia). Faz-me sempre umas perguntas que me deixam mudo e desconcertado. No ano passado, estávamos em minha casa, em Abril, e ele tinha um caracol na mão. (...) Gostei que ele não tivesse repugnância pelo animal e que o estivesse a observar atentamente. Até que me perguntou: É tão lento porquê? (...) Meu Deus, o que é que the respondo? Que não lhe podemos dar corda? Vou falar-lhe do sistema muscular do caracol? (...) Pedi-Ihe tempo para pensar. (PIMENTA, 2013, s/p)

E assim nasceu, de acordo com o escritor, "a história de um caracol que descobre a importância e o prazer de ser lento, de não andar mais rápido do que o necessário" (PIMENTA, 2013, s/p). Na sua demanda por um nome e pela razão da lentidão dos caracóis do jardim, o jovem caracol conhece uma coruja melancólica e uma tartaruga sábia, encetando com esta última uma viagem até ao extremo do prado, que os caracóis mais velhos chamavam "o fim da vida" (SEPÚLVEDA, 2014, p. 44). Nessa curta viagem iniciática, que é também o lugar da afetividade e da partilha de saberes e de sonhos, o jovem caracol acede ao conhecimento: ele aprende o significado de três palavras novas, fundamentais na sua vida futura - exílio, memória e rebeldia - e conhece igualmente a importância da lentidão. Foi graças ao 
caminhar lentamente que o jovem caracol pôde encontrar e estabelecer uma relação intersubjetiva com a tartaruga sábia, vislumbrando outras realidades, para além do seu horizonte visual e simbólico.

Conhecedor do futuro trágico que espera todos os habitantes do verde prado, Rebelde, o jovem caracol, decide regressar atrás para avisar os seus companheiros e é ele quem vai liderar, apesar das vozes dissonantes dos caracóis mais velhos que receiam perder a autoridade, a longa e ousada travessia em busca de um novo Éden, o País do Dente-de-Leão.

Autêntico elogio à amizade, à memória, à fraternidade, à comunhão e ao diálogo entre os seres, ao inconformismo, à capacidade de iniciativa mesmo quando a maioria se opõe, esta é uma obra que singelamente interroga o seu leitor e o impele a ser ativo, não conformista, a perseguir os seus sonhos. Querer é acreditar e, dentro de cada um, está a força que o impele a nunca olhar para trás e a agir!

Tal como na primeira obra, anteriormente analisada, também aqui é nítida uma clara dicotomia entre os animais e os humanos, os últimos agindo sem ter em conta o Outro, o seu habitat ou a sua sobrevivência.

Múltiplos planos se cruzam nesta obra: elementos que remetem para a verticalidade em oposição à horizontalidade, 
a que se associam simbolicamente aspetos como os da dicotomia céu/terra, vida/morte, luz/sombra ou ainda comunhão/separação ou utopia/distopia.

É elevando-se acima da Tartaruga ou ao cimo das longas hastes da flor do calicanto que os caracóis podem vislumbrar uma outra realidade e, munidos de uma visão projetiva, modificar a sua sorte.

No fundo, esta fábula vem mostrar aos seus leitores que há sempre uma razão, mesmo que aparentemente não patente, para determinadas situações ou eventos, cabendo a cada um, consoante a sua determinação, ousadia e coragem, descobri-la. A descoberta é, muitas vezes, uma autodescoberta, ou seja, é pela relação intersubjetiva que podemos conhecer e perspetivar outras realidades e conhecermo-nos melhor a nós próprios. Por outro lado, esta fábula mostra igualmente aos seus leitores que eles devem acreditar em si próprios e enfrentar os seus medos. Parar nunca é solução. O caminho faz-se caminhando e é nos mais jovens, curiosos e insatisfeitos por natureza, que reside a chave para um futuro coletivo mais proveitoso e auspicioso:

- Cumpriste a tua palavra. Trouxeste-nos até ao País do Dente-de-Leão - disse um caracol, entusiasmado.

- Não - começou Rebelde a dizer, num murmúrio - , eu não vos trouxe. Mas, nesta 
viagem que começou quando quis ter um nome, descobri muitas coisas. Descobri a importância da lentidão e, agora, que o País do Dente-de-Leão, à força de tanto o desejarmos, estava dentro de nós próprios - acabou ele de sussurrar e lentamente, muito lentamente, foi juntar-se aos seus companheiros para comer. (SEPÚLVEDA, 2014, p. 104)

\section{CONCLUSÕES}

Sendo textos de potencial recepção leitora infanto-juvenil, há nestas três curtas narrativas uma clara preocupação com uma educação para os valores, uma educação para a tolerância, para o respeito pelo Outro. O Outro é dado a ler nas suas diferenças e estas são não apenas respeitadas, mas entendidas como elementos positivos e complementares para o entendimento dos sujeitos. Esta preocupação com o Outro, particularmente com o Outro a quem, usualmente, é negada a Voz e a capacidade de Ação, tem sido enfatizada pelo autor em diversos textos de natureza ensaística ou autobiográfica, como ocorre, por exemplo, em Palavras em tempos de crise (SEPÚLVEDA, 2013b).

Obedecendo a leitura destas fábulas ao protocolo da ficcionalidade, elas não deixam, porém, de suscitar, nos seus leitores, importantes e significativos efeitos perlocutivos. Com efeito, mantendo uma natureza estética, elas 
possibilitam interrogar o mundo e suscitar uma reflexão lata sobre os valores, em particular os valores da Alteridade e do seu reconhecimento pelo sujeito: quem é o Outro no meu diaa-dia? Como devo lidar com Ele? O que é que é fundamental na relação intersubjetiva? Por que razão pensamos o mundo de uma certa forma e agimos em conformidade? Será possível pensar o mundo de modos mais enriquecedores e respeitadores de todos os seres que o habitam?

Concluímos com a voz de Luís Sepúlveda, que cria histórias para os pequenos leitores (nas suas palavras) em que possa partilhar princípios, "Valores divertidos de descobrir. Quero provar com as fábulas que é possível unir esforços." (PIMENTA, 2013, s/p) e, acrescentamos nós, tornar o mundo melhor.

\section{REFERÊNCIAS}

AZEVEDO, Fernando. (2011). Poder, Desejo, Utopia. Estudos em Literatura Infantil e Juvenil. Braga: CIFPEC - Centro de Investigação em Formação de Profissionais de Educação da Criança / Instituto de Educação, Universidade do Minho.

BRESSAN, Tullio. (1984). Sentieri di Luce. Teoria della Letteratura Giovanile. Trieste: L'Ora del Racconto.

CAZENAVE, Michel. (Dir.) (2007). Encyclopédie des Symboles. Astrologie, Cabale, Mythes, Nombres, Alchimie, Divinités et Croyances, Héros et Légendes. Paris: Le Livre de Poche / Librarie Générale Française.

CESARINY, Mário. (1980). Primavera autónoma das estradas. Lisboa: Assírio \& Alvim. 
FONSECA, António Manuel. (2000). Educar para a cidadania. Porto: Porto Editora INNOCENTI, Orsetta. La Letteratura Giovanile. Roma - Bari: Gius Laterza \& Figli / Editori Laterza.

PATRICIO, Manuel Ferreira. (1996). Formation des enseignants et éducation axiologique. In: Anais. 18th Annual Conference of the Association for Teacher Education in Europe. Lisboa: Universidade de Lisboa. p. 103-120. PIMENTA, Rita. Luís Sepúlveda: o escritor que já foi um gato. Público. Lisboa. In: https://www.publico.pt/culturaipsilon/noticia/luis-sepulvedao-escritor-que-ja-foi-um-gato-1596836. Acesso em 15 de fev. 2016.

PIRES, Maria Natividade. (1996). "Literatura infantil e educação multicultural." Inovação, 9, p. 99-105.

SEPÚLVEDA, Luís. (2002). História de uma gaivota e do gato que a ensinou a voar. Porto: Edições Asa.

SEPÚLVEDA, Luís. (2013a). História de um gato e de um rato que se tornaram amigos. Porto: Porto Editora.

SEPÚLVEDA, Luís. (2013b). Palavras em tempos de crise. Porto: Porto Editora. SEPÚLVEDA, Luís. (2014). História de um caracol que descobriu a importância da lentidão. Porto: Porto Editora.

\footnotetext{
1 Este trabalho foi financiado por Fundos Nacionais através da FCT (Fundação para a Ciência e a Tecnologia) e cofinanciado pelo Fundo Europeu de Desenvolvimento Regional (FEDER) através do COMPETE 2020 - Programa Operacional Competitividade e Internacionalização (POCI) no âmbito do CIEC (Centro de Investigação em Estudos da Criança da Universidade do Minho) com a referência POCI-01-0145-FEDER-007562
}

Ângela Balça. Doutorada em Ciências da Educação. Universidade de Évora, Portugal. Atuação em Doutoramento, Mestrado e Licenciatura, nas áreas de Literatura Infantil, Formação do Leitor e Educação Literária. Autora da obra Literatura Infantil e Juvenil e Formação de Leitores, publicada em 2013, pela Editora Santillana. Membro do Centro de Investigação em Estudos da Criança da Universidade do Minho.apb@uevora.pt

Fernando Azevedo. Doutorado em Ciências da Literatura. Universidade do Minho, Portugal. Atuação em Doutoramento, Mestrado e Licenciatura, nas áreas de Literatura Infantil, Formação do Leitor e 
Educação Literária. Autor da obra Literatura para Crianças e Jovens. Da Memória ao Leitor, publicada em 2015, pela Universidade do Minho. Membro do Centro de Investigação em Estudos da Criança da Universidade do Minho. fraga@ie.uminho.pt

Recebido em 20 de março de 2016. Aprovado em 1 de abril de 2016. 